九州大学学術情報リポジトリ

Kyushu University Institutional Repository

Comparison of molecular models used in molecular dynamics simulation for tracer diffusion coefficients of naphthalene and dimethylnaphthalene isomers in supercritical carbon dioxide

Higashi, Hidenori

Division of Material Engineering, Graduate School of Natural Science and Technology, Kanazawa University

Iwai, Yoshio

Department of Chemical Engineering, Faculty of Engineering, Kyushu University

Arai, Yasuhiko

Department of Chemical Engineering, Faculty of Engineering, Kyushu University

http://hdl. handle. net/2324/12531

出版情報 : Fluid Phase Equilibria. 234 (1-2)，pp.51-55，2005-08-08. Elsevier バージョン:

権利関係: (C) 2005 Elsevier B. V. All rights reserved. 
A paper submitted to Fluid Phase Equilibria

Revised manuscript (HI-04-33)

\title{
Comparison of Molecular Models used in Molecular Dynamics Simulation for Tracer Diffusion Coefficients of Naphthalene and Dimethylnaphtalene Isomers in Supercritical Carbon Dioxide
}

\author{
Hidenori HIGASHI ${ }^{1, *}$, Yoshio IWAI $^{2}$ and Yasuhiko $\mathrm{ARAI}^{2}$ \\ ${ }^{1}$ Division of Material Engineering, Graduate School of Natural Science \& Technology, \\ Kanazawa University, \\ Kakuma-machi, Kanazawa 920-1192, Japan \\ ${ }^{2}$ Department of Chemical Engineering, Faculty of Engineering, Kyushu University, \\ 6-10-1 Hakozaki, Higashi-ku, Fukuoka 812-8581, Japan \\ * Corresponding Author \\ higashi@t.kanazawa-u.ac.jp, +81-76-264-6260
}




\begin{abstract}
NVT ensemble molecular dynamics simulation was performed to calculate the tracer diffusion coefficients of naphthalene and dimethylnaphthalene isomers in supercritical carbon dioxide. Carbon dioxide was treated as a Lennard-Jones molecule (single site model) and solutes were treated as a rigid model of multi sites (united atom model) and a flexible model of all atoms (all atom model). The calculated results are compared with the experimental data and the calculated results by a single site model. The united atom model gives the best results to the experimental data among the three models. The calculated tracer diffusion coefficients by the all atom model show fairly good results without adjustable interaction parameters.
\end{abstract}

Keywords : Molecular Simulation, Molecular Model, Diffusion Coefficient, Supercritical Carbon Dioxide 


\section{Introduction}

One of important physical properties necessary to the design of supercritical extractor, separator and reactor is the diffusion coefficients of solutes in supercritical fluids. However, measurement of diffusion coefficients under the supercritical conditions is difficult so that the diffusion coefficient data in the supercritical region are quite limited. Computer simulation may be feasible and helpful to obtain thermodynamic data for mixtures under high pressure.

Recently, molecular dynamics (MD) simulation has been applied widely to calculate physical properties due to the rapid development of high speed computers. The Lennard-Jones potential is commonly adopted for intermolecular potential. Yamaguchi et al. [1] performed the MD simulation for a system interacting the Lennard-Jones potential and investigated the solvent density effect on the diffusion coefficients in supercritical fluids. Coelho et al. [2] proposed the correlation method for self-diffusion coefficients in dense fluid by using the perturbation theory coupled with smooth-hard sphere theory and tested against molecular simulation and experimental data. They also performed the MD simulation. Zhou et al. [3] applied the MD simulation to calculate the infinite dilute diffusion coefficient of organic compounds in supercritical carbon dioxide. Drozdov and Tucker [4] used the results of molecular dynamics simulation to evaluate the behavior of the self-diffusion coefficient in the critical region and they found a weakly anomalous behavior at near critical densities. Egorov [5] proposed a mode-coupling theory and compared the results of diffusion coefficient obtained by the theory and by molecular simulation. The theory shows a good agreement with the simulation.

In previous works $[6,7]$, the authors have applied single site model MD simulation to calculate the tracer diffusion coefficients of aromatic compounds, such as 2,6- and 2,7-dimethylnaphthalene, in supercritical carbon dioxide under the infinite dilution condition. The calculated results showed fairly good correlation. However, the calculated diffusivities 
were smaller than the experimental results, as increasing the molecular weight. As a result, the assumption of sphere, such as single site model, is not suitable for the complicated compounds. More accurate models for complicated compounds are necessary to represent the diffusion coefficients of solute in supercritical fluid. In this work, as an extension, the tracer diffusion coefficients of naphthalene and dimethylnaphthalene isomers in supercritical carbon dioxide were calculated by the MD simulation and the influence of molecular models on diffusion coefficients was discussed. The simulations by the single site model for 2,3-dimethylnaphthalene, those by the united atom model and those by the all atom model for naphtharene and dimethylnaphthalene isomers are carried out in this work.

\section{Simulation Methods}

\subsection{Models and Potential Functions}

Carbon dioxide was treated as a Lennard-Jones molecule (single site model) and solutes were treated as a single site model, a rigid model of multi sites (united atom model) and a flexible model of all atoms (all atom model). The Lennard-Jones (12-6) potential function was used for all sites in the simulation,

$$
\phi\left(r_{i j}\right)=4 \varepsilon_{i j}\left\{\left(\frac{\sigma_{i j}}{r_{i j}}\right)^{12}-\left(\frac{\sigma_{i j}}{r_{i j}}\right)^{6}\right\}
$$

where $\varepsilon$ is the energy parameter, $\sigma$ is the size parameter, $r$ is the distance, and $i$ and $j$ denote the sites $i$ and $j$, respectively.

\subsection{Parameters}

\subsubsection{Carbon dioxide}

The potential parameters for the single site model of carbon dioxide were referred from the model proposed by Iwai et al. [6]. These parameters were determined by the PVT behavior of pure carbon dioxide. The parameters of single site model for carbon dioxide used 
in the present study are listed in Table $\mathbf{1 .}$

\subsubsection{Solute}

\section{a) Single site model}

The simulation for carbon dioxide +2 ,3-dimethylnaphthalene system by the single site model of solute was performed in the present work and others were cited from the previous works $[6,7]$. The energy and size parameters were determined by the critical temperature and pressure as the same procedure reported by the previous works [6, 7]. The parameters of single site model for solute used in the present study are listed in Table 1. The interaction parameters between supercritical carbon dioxide(1) and solute(2) are given as

$$
\begin{aligned}
& \varepsilon_{12}=\left(1-k_{12}\right)\left(\varepsilon_{11} \varepsilon_{22}\right)^{1 / 2} \\
& \sigma_{12}=\left(1-l_{12}\right)\left(\sigma_{11}+\sigma_{22}\right) / 2
\end{aligned}
$$

where $k_{12}$ and $l_{12}$ are the intermolecular interaction parameters between unlike molecules. The interaction parameters were determined to represent the solubility in supercritical carbon dioxide by using Monte Carlo simulation. The details of the Monte Carlo simulation are explained in the previous paper $[6,7]$ and the calculation procedures were reported previously [8]. The systems consist of 108 particles of carbon dioxide in a cubic cell with periodic boundary conditions. The standard Metropolis importance sampling method [9] was used to obtain new configurations. Widom's test particle method [10] was adopted to calculate the residual chemical potentials for aromatic compounds in supercritical carbon dioxide. After 2.0 $\times 10^{5}$ configurations of carbon dioxide were generated to reach equilibrium condition, a test particle was tried to place at random locations 50 times for 50 configurations of carbon dioxide. The length of calculations were $5.0 \times 10^{6}$ to $1.8 \times 10^{7}$ configurations of carbon dioxide. The values of interaction parameters for 2,3-dimethylnaphthalene $\left(k_{i j}=0.10\right.$, $\left.l_{i j}=0.05\right)$ are the same as those for 2,6- and 2,7-dimethylnaphthalene. The interactions between 
carbon dioxide and dimethylnaphthalene isomers are considered to be almost the same. So, all the adjustable parameters are the same for dimethylnaphthalene isomers. Furthermore, the difference of solubilities for dimethylnaphthalene isomers is due to the difference of vapor pressure.

b) United atom model

The tracer diffusion coefficients of solutes in supercritical carbon dioxide were calculated at infinite dilution condition. In the calculation, the interaction between solute and solute is not necessary. The interactions between supercritical carbon dioxide and solutes are needed. The potential parameters for the united atom model of solute are determined to represent the solubility in supercritical carbon dioxide by using the Monte Carlo simulation in the present work. The size and energy parameters for benzene ring site were determined by the solubility data of naphthalene and those of methyl group were determined by the solubility data of dimethylnaphthalene isomers. The data about 15MPa were used for the correlation. The residual chemical potentials of the solutes in supercritical carbon dioxide were calculated by the test particle method proposed by Widom [10]. Details of the calculation procedure for the solubility were reported previously [11-14]. The systems consisting of 108 particles of carbon dioxide in a cubic cell with periodic boundary conditions. After $5.0 \times 10^{5}$ configurations of carbon dioxide were generated to reach equilibrium condition, a test particle was tried to place at random locations 50 times for 50 configurations of carbon dioxide. When the test particle did not overlap with real particles of carbon dioxide, a solute molecule was placed on the position of the test particle and was rotated to sample the potential energies experienced for the purpose of more effective sampling. On the other hand, when the test particle overlapped with real particles, the potential energy experienced by the solute placed on the position should be infinite. So, it is not necessary to calculate the potential energy. The number of rotations against one insertion of the test particle was 50 . The 
length of simulations were $3.0 \times 10^{7}$ configurations of carbon dioxide. The distance of the centers for two benzene ring sites and that between the center of benzene ring site and that of methyl group site were $0.242 \mathrm{~nm}$ and $0.292 \mathrm{~nm}$, respectively. These values were cited from the literature $[11,12]$. The arithmetic and geometry combining rules were used to calculate the size and energy parameters between unlike molecules. The parameters of united atom model for solute used in the present study are listed in Table 1. The calculated results of solubilities were shown in Figure 1.

\section{c) All atom model}

The simulation by the all atom model of solute was performed by the Ceius ${ }^{2}$ software (Molecular Simulation Inc.) and the Universal force field [15] contained in the software was mainly adopted to the simulation. The parameters for the all atom model of solute were adopted from the Universal force field in the software. The arithmetic and geometry combining rules were used to calculate the size and energy parameters between unlike molecules. The parameters of all atom model for solute used in the present study are listed in Table 1.

\subsection{Simulation Conditions and Analysis}

$N V T$ ensemble MD simulation was applied to calculate the tracer diffusion coefficients of solute in supercritical carbon dioxide. The simulations were performed at $308.2 \mathrm{~K}$. The time step of the calculations was set to $1 \mathrm{fs}$. The time step, $1 \mathrm{fs}$, was short enough to prevent from particle overlapping also for all atom model. The SHAKE algorithm[16] was applied to keep the shape of solute molecule for the simulation by united atom model. The simulation conditions were listed in Table 2. The systems are assumed to be at the infinite dilution condition of solute and the cut-off length was set to be the half-cell. The calculated diffusion 
coefficients are considered to correspond to the infinite dilution diffusion coefficients of the solute in supercritical carbon dioxide. The diffusion coefficients were calculated by mean square displacement (MSD) of the center of mass for the solute molecule,

$$
D=\lim _{t \rightarrow \infty} \frac{1}{6 t}\left\langle[\mathbf{r}(t)-\mathbf{r}(0)]^{2}\right\rangle
$$

where $\mathbf{r}$ is the position of particles and $t$ is the time. The diffusion coefficients were calculated by the slope of MSD between 2 to 10 ps.

\section{Results and Discussion}

The simulated results for tracer diffusion coefficients of naphthalene and dimethylnaphthalene isomers are shown in Figures 2-5. Although the adjustable parameters determined by the solubility data were used for the simulations by the single site and the united atom models, no adjustable parameter were adopted in the simulations by the all atom model.

The simulated results of dimethylnaphthalene isomers are slightly smaller than those of naphthalene, and the difference among the diffusion coefficients calculated by MD in the present study for dimethylnapjhthalene isomers was not remarkable for the potential models used in this wrok.

The simulated results of this work ant literature $[6,7]$ by the single site model are slightly smaller than the experimental results, because the approximation of Lennard-Jones sphere is extreme and the diameters of the solute molecules are large.

The simulated results by the united atom model for naphthalene are almost the same as those by the single site model and show a good agreement with the experimental results. However, the density dependence of diffusion coefficients by the single site model is larger than the experimental results, simulated results by the united atom model and those by the all 
atom model. As especially shown in Figure 5, the simulated results by the united atom model for dimethylnaphthalene isomers are slightly larger than the results by single site model in previous works [6, 7] for 2,6- and 2,7-dimethylnaphthalene and this work for 2,3-dimethylnaphthalene, and are close to the experimental data. As the united atom model reflects the shape of molecules, the simulated results by the model were better than those by the single site model.

The simulated results by the all atom model are almost the same as those by the single site model and are slightly smaller than the experimental data. The all atom model seems to be fairly good without any adjustable parameters in the simulation.

The density of the system is most effective to the diffusivity in supercritical fluid. So the simulated results by three model used in this work show similar results. According to the results, the single site model is too simple and need two adjustable parameters. The united atom model's parameters are adjusted to the solubility data. However, the model is in moderation and will be available to many systems. The all atom model has no adjustable parameters but the model is too complicated for the calculation of diffusion coefficients.

\section{Conclusions}

The molecular dynamics simulation was performed to calculate the tracer diffusion coefficients of solute in supercritical carbon dioxide under the infinite dilution condition. The influence of molecular models used in the simulation was investigated. In any cases, the diffusion coefficients of solute in supercritical carbon dioxide by molecular dynamics simulations can represent the reasonable results compared with the experimental data. The united atom model can represent both the solubilities and diffusion coefficients of solutes in supercritical carbon dioxide. The simulated results by the all atom model show a fairly good agreement with the experimental results without adjustable parameters for the binary systems. 


\section{List of Symbols}

D diffusion coefficient, $\mathrm{m}^{2} \mathrm{~s}^{-1}$

$P \quad$ pressure, $\mathrm{Pa}$

$r \quad$ distance, $\mathrm{m}$

$\mathbf{r} \quad$ position of particles, $\mathrm{m}$

$t$ time, $\mathrm{s}$

$y_{2} \quad$ solubility (mole fraction), -

Greek letters

$\varepsilon \quad$ energy parameter, $\mathrm{J}$

$\rho \quad$ density, $\mathrm{kg} \mathrm{m}^{-3}$

$\sigma \quad$ size parameter, $\mathrm{m}$

$\phi \quad$ potential, $\mathrm{J}$

Subscripts

$i, j \quad$ sites $i$ and $j$

\section{References}

[1] T. Yamaguchi, Y. Kimura, N. Hirota, Mol.Phys. 94 (1998) 527-537.

[2] L. A. F. Coelho, J. V. Oliveira, F. W. Tavares, Braz.J.Chem.Eng. 16 (1999) 319-328.

[3] J. Zhou, X. H. Lu, Y. R. Wang, J. Shi, Fluid Phase Equilibria 172 (2000) 279-291.

[4] A. N. Drozdov, S. C. Tucker, J.Chem.Phys. 114 (2001) 4912-4917.

[5] S. A. Egorov, J.Chem.Phys. 119 (2003) 4798-4810.

[6] Y. Iwai, H. Higashi, H. Uchida, Y. Arai, Fluid Phase Equilibria 127 (1997) 251-261.

[7] H. Higashi, Y. Iwai, H. Uchida, Y. Arai, J.Supercrit.Fluids 13 (1998) 93-97.

[8] Y. Iwai, Y. Koga, Y. Hata, H. Uchida, Y. Arai, Fluid Phase Equilibria 104 (1995) 
403-412.

[9] N. Metropolis, A. W. Rosenbluth, M. N. Rosenbluth, A. H. Teller, E. Teller, J.Chem.Phys. 21 (1953) 1087-1093.

[10] B. Widom, J.Chem.Phys. 39 (1963) 2808-2812.

[11] Y. Iwai, H. Uchida, Y. Koga, Y. Mori, Y. Arai, Fluid Phase Equilibria 111 (1995) $1-13$.

[12] Y. Iwai, H. Uchida, Y. Koga, Y. Arai, Y. Mori, Ind.Eng.Chem.Res. 35 (1996) 3782-3787.

[13] Y. Iwai, H. Uchida, Y. Arai, Y. Mori, Fluid Phase Equilibria 144 (1998) 233-244.

[14] Y. Iwai, Y. Mori, Y. Arai, Fluid Phase Equilibria 167 (2000) 33-40.

[15] A. K. Rappe, C. J. Casewit, K. S. Colwell, W. A. Goddard, W. M. Skiff, J.Amer.Chem.Soc. 114 (1992) 10024-10035.

[16] J. P. Rychaert, G. Ciccotti, H. J. C. Berendsen, J.Comp.Phys.,23 (1977) 327-341.

[17] D. Brown, J. H. R. Clarke, Mol.Phys. 51 (1984) 1243-1252.

[18] Y. V. Tsekhanskaya, M. B. Iomtev, E. V. Mushkina, Russ.J.Phys.Chem. 38 (1964) 1173-1176.

[19] H. Higashi, Y. Iwai, Y. Nakamura, S. Yamamoto, Y. Arai, Fluid Phase Equilibria 166 (1999) 101-110.

[20] R. T. Kurnik, S. J. Holla, R. C. Reid, J.Chem.Eng.Data 26 (1981) 47-51.

[21] Y. Iwai, Y. Mori, N. Hosotani, H. Higashi, T. Furuya, Y. Arai, K. Yamamoto, Y. Mito, J.Chem.Eng.Data 38 (1993) 509-511. 
Table 1 Potential parameters

\begin{tabular}{|c|c|c|c|}
\hline Model & Site & $\sigma[\mathrm{nm}]$ & $\varepsilon / k[\mathrm{~K}]$ \\
\hline \multirow[t]{5}{*}{ Single site } & Carbon dioxide & $0.372^{\text {a) }}$ & $236.1^{\text {a) }}$ \\
\hline & Naphthalene & $0.654^{\text {a) }}$ & $554.4^{\text {a) }}$ \\
\hline & 2,3-Dimrthylnaphthalene & $0.729^{b)}$ & $577.2^{b)}$ \\
\hline & 2,6-Dimrthylnaphthalene & $0.727^{\mathrm{c})}$ & $570.8^{c)}$ \\
\hline & 2,7-Dimrthylnaphthalene & $0.727^{\mathrm{c})}$ & $571.1^{\mathrm{c})}$ \\
\hline \multirow[t]{2}{*}{ United atom } & Benzene ring & $0.448^{\mathrm{d})}$ & $322.4^{d)}$ \\
\hline & Methyl group & $0.300^{\mathrm{d})}$ & $90.4^{\mathrm{d})}$ \\
\hline \multirow[t]{2}{*}{ All atom } & $\mathrm{C}$ & $0.343^{\mathrm{e})}$ & $52.9^{\text {e) }}$ \\
\hline & $\mathrm{H}$ & $0.257^{\mathrm{e})}$ & $22.2^{\mathrm{e})}$ \\
\hline
\end{tabular}

a) Iwai et al. [6]

b) Determined by critical temperature and pressure in this work.

c) Higashi et al. [7]

d) Adjusted to the solubility data in this work.

e) Universal force field [15] 
Table 2 Simulation conditions

\begin{tabular}{|c|c|c|c|}
\hline Model & Temperature control & Number of molecules & Simulation steps \\
\hline \multirow{2}{*}{ Single site } & Constraint method & Carbon dioxide : 255 & Equilibration : $5.0 \times 10^{3}$ \\
\hline & (Brown and Clarke [17]) & Solute : 1 & Production : $2.0 \times 10^{6}$ \\
\hline \multirow{2}{*}{ United atom } & Constraint method & Carbon dioxide : 255 & Equilibration : $5.0 \times 10^{3}$ \\
\hline & (Brown and Clarke [17]) & Solute : & Production : $2.0 \times 10^{6}$ \\
\hline \multirow{2}{*}{ All atom } & \multirow{2}{*}{ Scaling method } & Carbon dioxide : 300 & Equilibration : $1.0 \times 10^{4}$ \\
\hline & & Solute : & Production : $1.0 \times 10^{6}$ \\
\hline
\end{tabular}


Figure captions

Fig.1 Solubilities of aromatic compounds in supercritical carbon dioxide at $308.2 \mathrm{~K}$.

Experimental: (— ) naphthalene, Tsekhanskaya et al. [18];

( - - - ) 2,3-dimethylnaphthalene, Higashi et al. [19] and Kurnik et al. [20];

(-.-.- ) 2,6-dimethylnaphthalene; ( - - - ) 2,7-dimethylnaphthalene, Iwai et al. [21].

MC calculations with the united atom model: $(\bigcirc)$ naphthalene;

( $\triangle$ ) 2,3-dimethylnaphthalene; $(\nabla$ ) 2,6-dimethylnaphthalene;

( $\square$ ) 2,7-dimethylnaphthalene.

Fig.2 Diffusion coefficients of naphthalene in supercritical carbon dioxide at $308.2 \mathrm{~K}$. Experimental: $(\bigcirc)$ ) Higashi et al. [19]; MD calculations: Single site model, (@) ) Iwai et al. [6]. United atom model of solute, ( $\bigcirc$ ) This work. All atom model of solute, ( ( ) This work.

Fig.3 Diffusion coefficients of 2,3-dimethylnaphthalene in supercritical carbon dioxide at 308.2 K. Experimental: ( $\triangle$ ) Higashi et al. [19]; MD calculations: Single site model, $(\Delta)$ This work. United model of solute, ( $\boldsymbol{\Delta}$ ) This work. All atom model of solute, ( $\Delta$ ) This work.

Fig.4 Diffusion coefficients of 2,6-dimethylnaphthalene in supercritical carbon dioxide at 308.2 K. Experimental: ( $\nabla$ ) Higashi et al. [19]; MD calculations: Single site model, ( $\nabla$ ) Higashi et al., [7]. United atom model of solute, ( $\nabla$ ) This work. All atom model of solute, $(\nabla)$ This work. 
Fig.5 Diffusion coefficients of 2,7-dimethylnaphthalene in supercritical carbon dioxide at 308.2 K. Experimental: ( $\square$ ) Higashi et al. [19]; MD calculations: Single site model, ( 回 ) Higashi et al., [7]. United atom model of solute, ( $\square$ ) This work. All atom model of solute, $(\square)$ This work. 


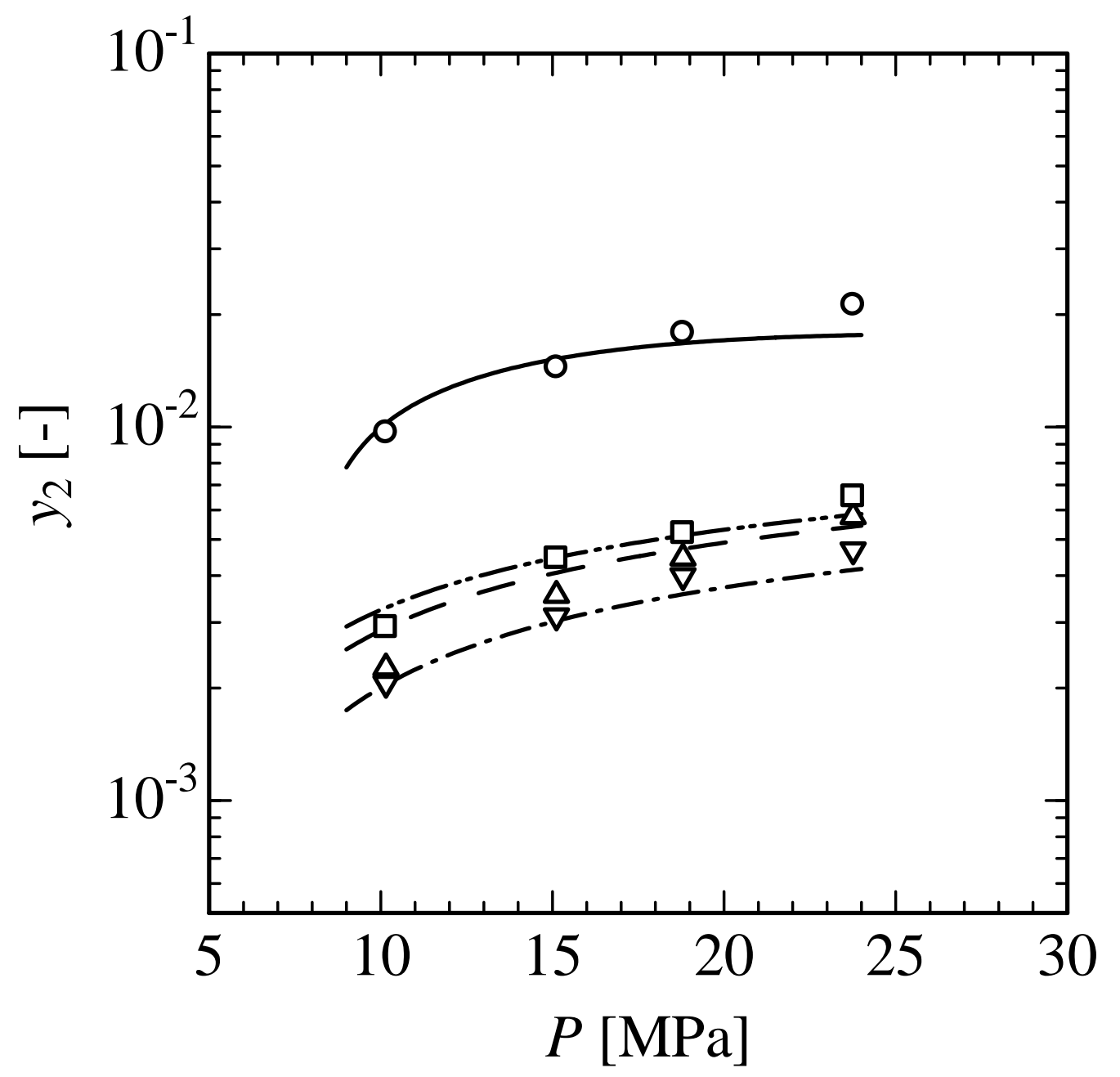

Fig.1 Higashi et al. 


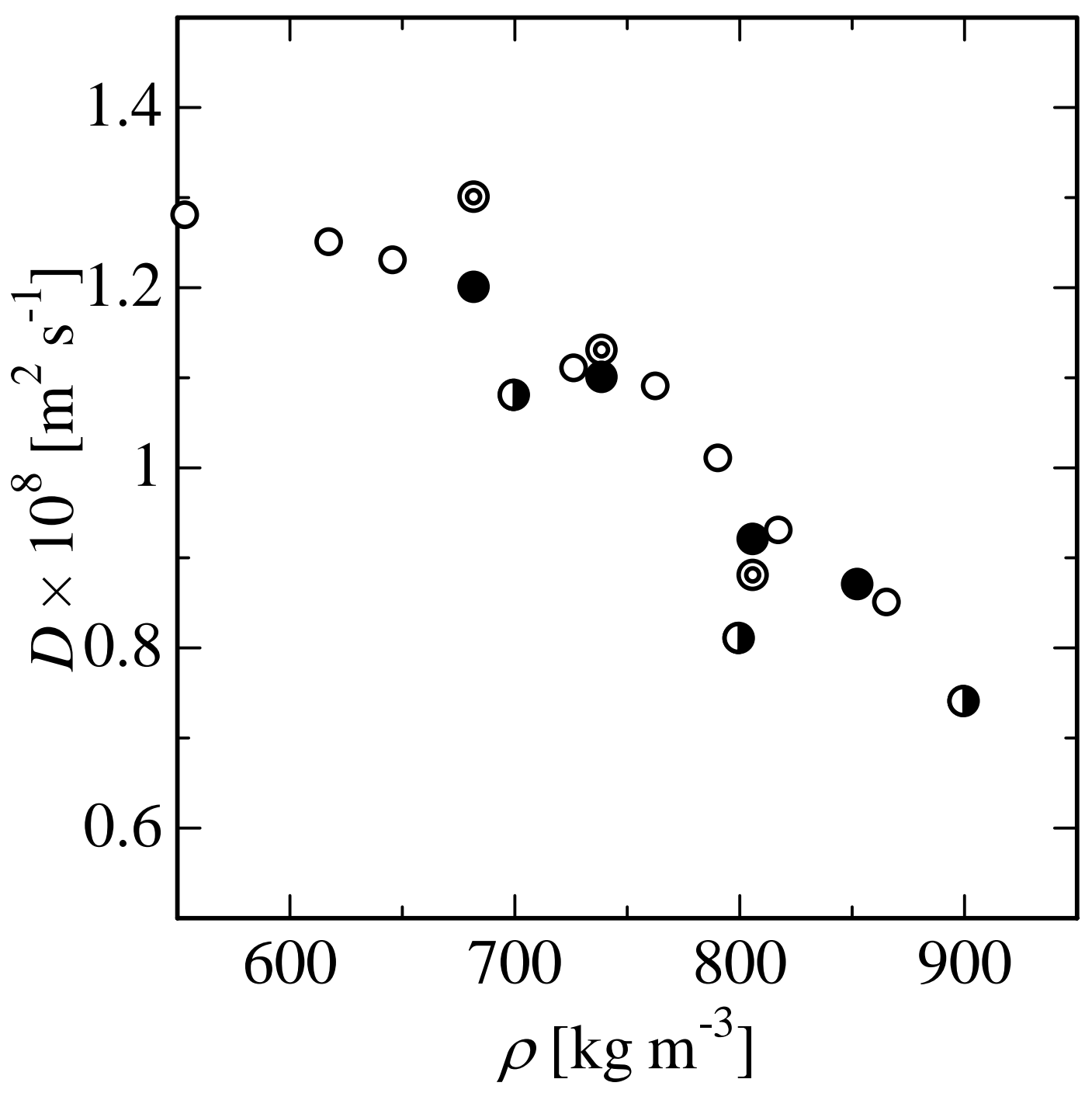

Fig. 2 Higashi et al. 


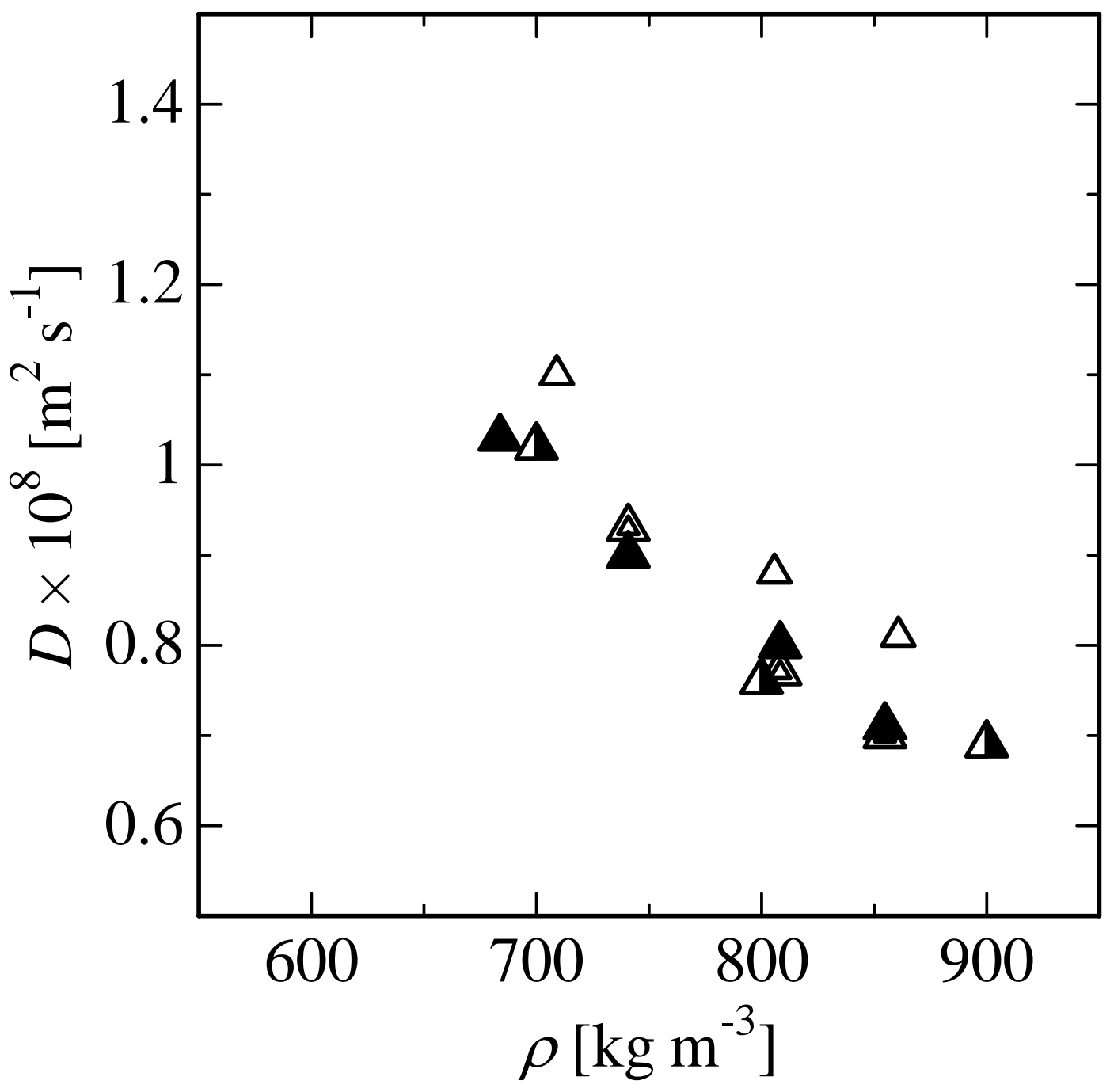

Fig. 3 Higashi et al. 


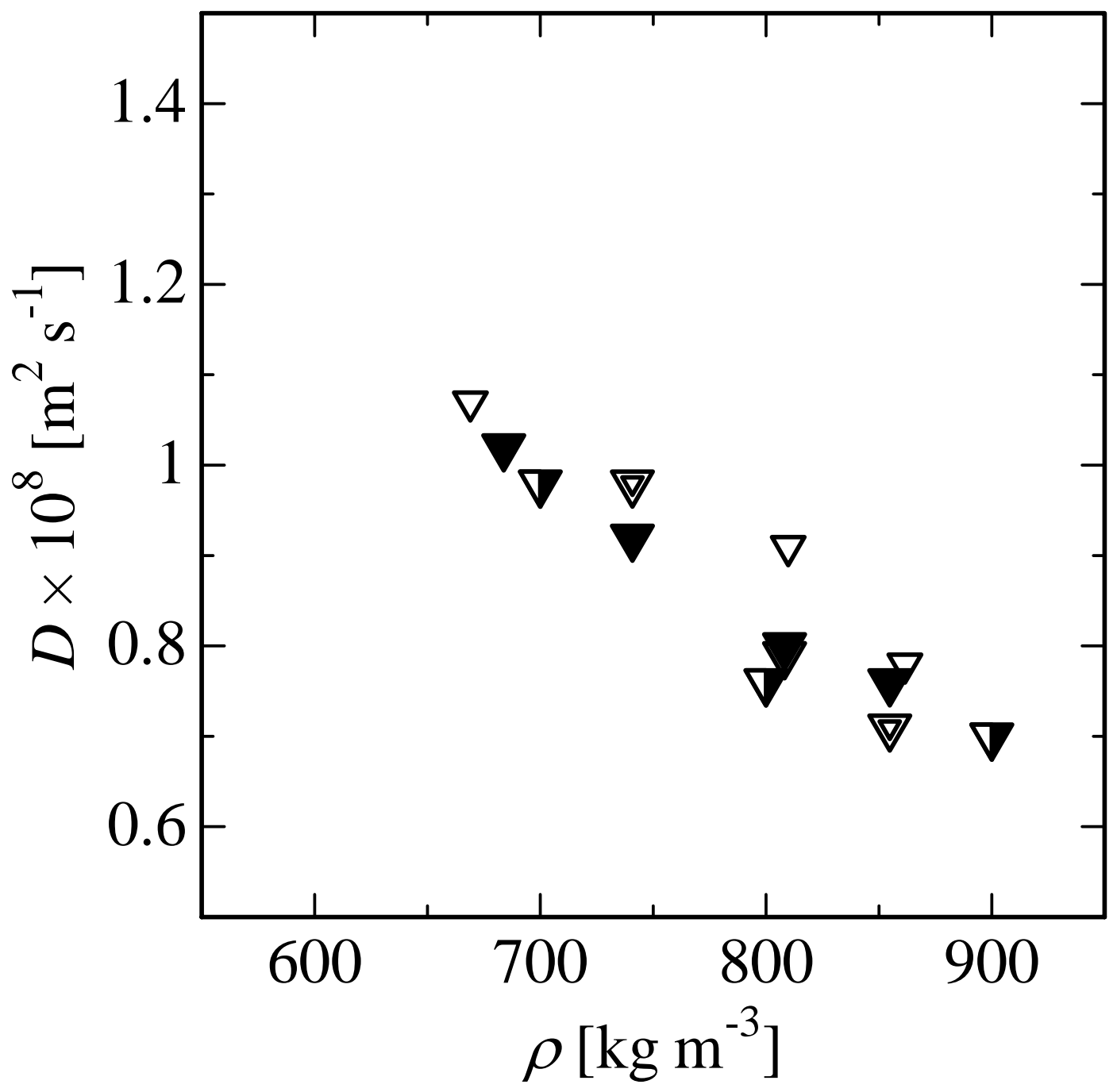

Fig. 4 Higashi et al. 


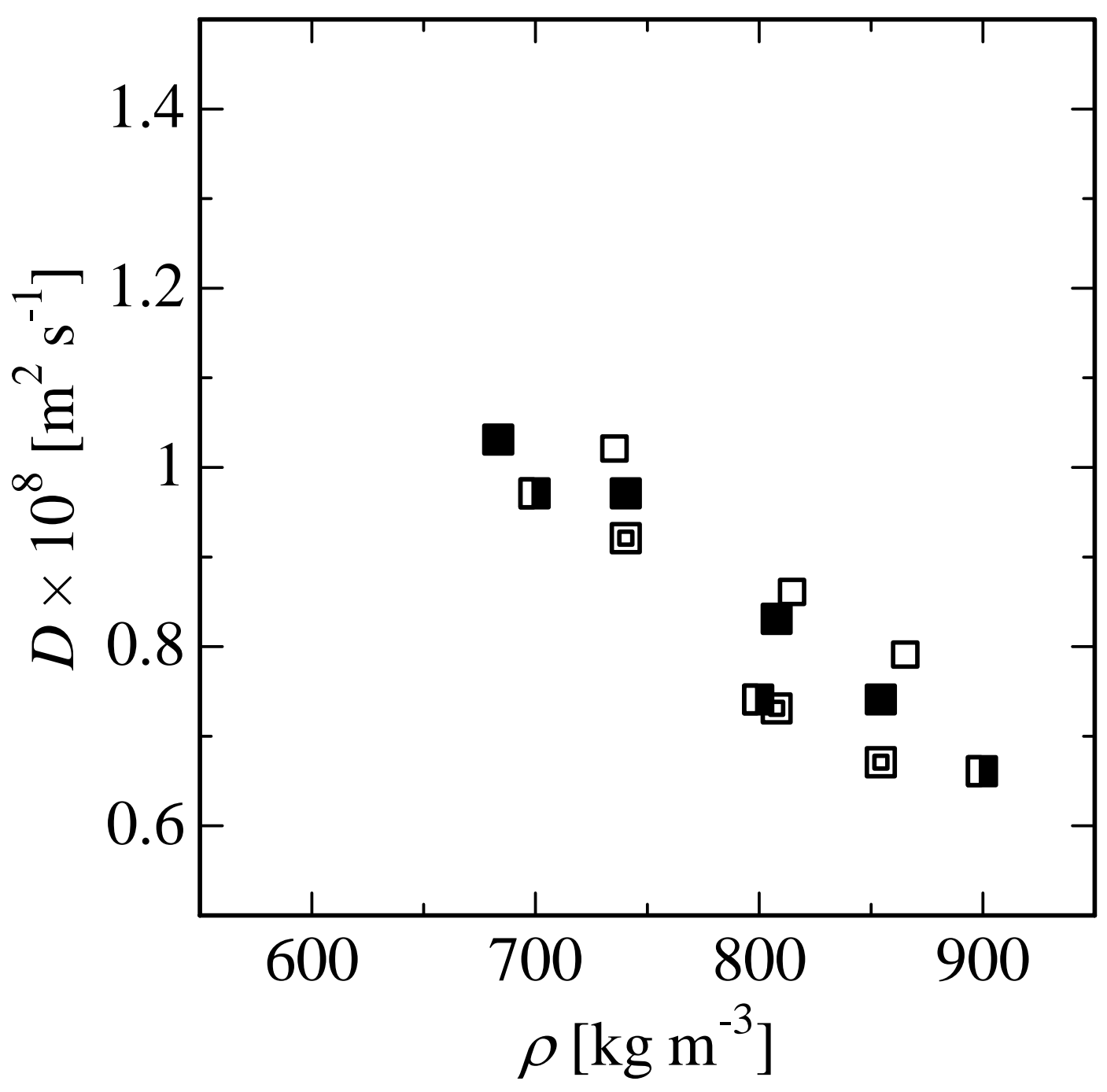

Fig. 5 Higashi et al. 